\title{
Analysis and evaluation of health and safety solutions in a construction site
}

\author{
Mohamad Khaled Abed El Rahim \\ Civil Engineering Department, Near East University, Nicosia, Mersin 10, Turkey
}

\section{A R T I CLE INFO}

ARTICLE HISTORY:

Received: 24 April 2020

Revised: 03 May 2020

Accepted: 14 May 2020

Published: 28 July 2020

\section{KEYWORDS:}

Occupational health and safety, fatalities, risk, construction site

\begin{abstract}
A B S T R A C T
The construction industry is one of the industries most vulnerable to accidents, to provide occupational health and safety solutions at the construction site it should know the problems workers may encounter at the site, analysis, and evaluation of these problems. The possible solutions depend on many cases such as the serious factors affecting the workers, who must avoid them, avoid the dangerous areas, analyse the architectural design and the building structure, etc. There are many solutions to determine occupational safety, such as the solution to the repeated problems which is applied based on general measures and criteria depending on the risk factor. This paper aims to analyse and assess the risks that construction workers can be exposed to at the construction site, and provide appropriate solutions to reduce the accidents by dividing tasks among all project participants and analysing some statistics on the number of fatalities and the types of accidents at the construction site.
\end{abstract}

\section{INTRODUCTION}

Statics indicate that there are more than 350,000 deaths and more than 270 million accidents every year in the world, for that reason, the question is how to assess risks and ensure occupational safety at the construction site that is the question must be analysis and the primary goal. Statistics were made that show a third of occupational injuries or a third of occupational deaths occurred at the construction site. Also, there are more violations of the regulatory legislation of health and safety registered in construction (Naujalis, 2009; Mitropoulos \& Memarian, 2012). Scientific and legal literature focuses on text solutions for all related problems on health and safety at work. In general, the causes of accidents on construction sites are divided into several sections, including mismanagement that concern the health and safety of workers, such as not subjecting workers to a qualifying course that allows them to know the bases for maintaining their health and safety in addition to making workers wear clothes that do not meet specifications another reason is the use of old equipment. It is not working, which leads to an increased rate of exposure to accidents. Other reasons threaten the health of all workers in implementing the project, including the lack of a health monitor for everyone, which leads to the spread of disease from one person to another.
Much research and law were specific in construction focus on the necessity of teamwork and that every member of the staff performs their specialized job while providing the appropriate atmosphere to avoid accidents. This article focuses on the causes of accidents and providing solutions to them through a discussion on training construction workers on health and safety methods on the one hand and on the other hand on the causes and occurrences of construction accidents and knowing their causes and benefiting from them to avoid similar accidents (Baxendale et al., 2000).

\section{METHODOLOGY}

The methodology is to analyse the causes of accidents, in addition to that several questionnaires that show the number of deaths occurring at the construction site in China, USA, Japan and Great Britain from 2013 to 2017. This is the first, and the second questionnaire is on the types of accidents in addition to the types of injuries. Finally, the analysis and interpretation of these questionnaires demonstrate the causes of these accidents, and solutions to reduce them in order to maintain worker safety. 


\subsection{Accidents and fatalities statics}

As we mentioned earlier, the construction industry is one of the most accident-prone industries, and statistics indicate the number of fatalities related to the construction site in China, the United States of America, Japan, and Great Britain from 2013 to 2017. These statistics indicate that the modified death rate in China is the most compared to other countries, where the number of deaths in China ranges between 1891 and 3,843 fatalities between 2013 and 2017 at the construction site. At the same time, Great Britain recorded the lowest percentage among the countries mentioned, and the number of fatalities ranged between 30 to 47 fatalities at the construction site (Guo et al., 2019). Fig. 1 summarizes the statistics of fatalities between 2013 and 2017.

As for the types of accidents, there are many types, for example falls, the collapse of an object, traffic. The rate of accidents varies from one type to another, as mention in Fig. 2 that falls rate is the highest one with a rate of $23.6 \%$ (Zhang et al., 2018).

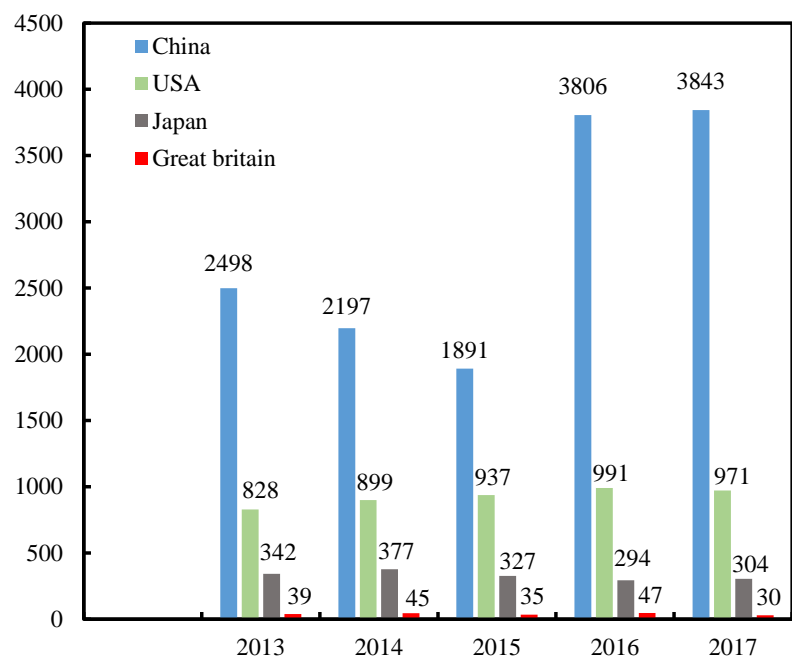

Fig. 1. Statistics of fatalities number between 2013 and 2017 in China, USA, Japan and Great Britain

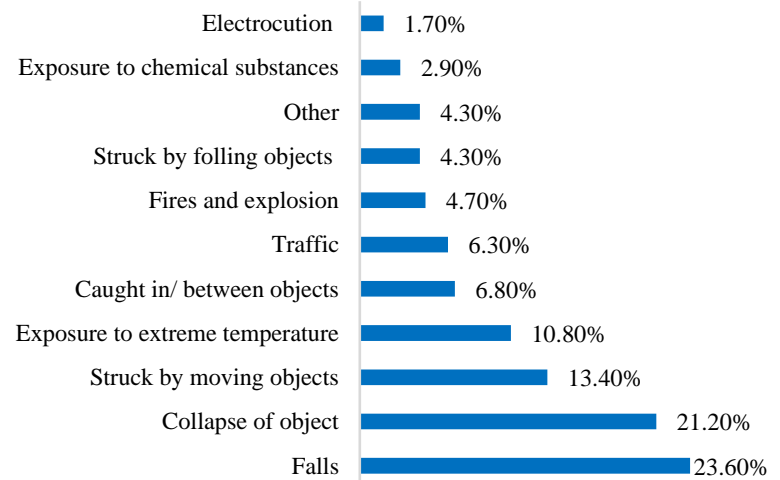

Fig. 2. Distribution of the accident types

\subsection{Accident damage to the worker's body}

There are many types of accidents workers may experience on the construction site. Each accident causes a specific injury to workers. Either this infection is minor and goes away over time, or it is a permanent injury, for example resulting in physical disability, or it can lead to psychological damage. Each worker on construction site experience on these types of accidents or to other types can be exposed to many types of serious injuries, for example, (Lingard, 2013):

- Burns,

- Electrocution,

- An eye injury that may lead to poor eyesight or blindness,

- Bone fractures,

- Fractures in the knee, ankle, neck, and back,

- Spinal cord damage and may result in paraplegia or quadriplegia,

- Serious and chronic diseases due to exposure to chemical substances,

- Head and brain injuries.

All of these injuries are serious injuries that lead to permanent bodily harm and sometimes psychological damage, for example, eye injury either leads to visual impairment or blindness which leaves great psychological pain from the injured, here lies the goal of this analysis and is to present the catastrophic results that may occur in a large percentage as a result of an accident on the construction site.

\subsection{Training for construction workers related to health and safety}

The two most likely reasons for insecurity and incidents that put workers at risk are:

- Insufficient knowledge of workers regarding health and safety principles,

- Lack of responsibility and attention to health and safety.

In these cases, lack of awareness among workers, on the one hand, and employers' lack of enthusiasm to train workers on the importance of health and safety and how to maintain them, may lead to accidents which sometimes leads to catastrophic results (Smolarz, 2019).

One of the main reasons that cause accidents in construction and building is also the use of non-usable equipment and the absence of qualified work teams to monitor the behaviour of workers if they work according to the appropriate conditions of health and safety, from here it must first secure the usable equipment and a dedicated team to monitor workers must be formed and analyse whether they are achieving safety requirements or are not interested in them, Strict decisions must also be made against religion that does not act according to the required conditions, (Abdul Hamid et al., 2008). It is also important for the health and safety team working to achieve the following 
laws defined by the International Labour Organization (2005).

\subsubsection{Laws of occupational health and safety}

Occupational health and safety have many laws. What we consider the most important of them internationally:

- Performing a medical examination at the beginning to verify the worker's physical and psychological health and knowing that he has the appropriate qualifications to work in order not to cause any harm to himself or other workers,

- Evaluate the risks that can occur and work to avoid them,

- Perform regular medical checks to avoid spreading disease and monitor the health of older workers,

- Training officials in first aid, providing emergency assistance and ensuring the correctness of the equipment and medicines used,

- Providing a clean and healthy environment for preparing and eating food.

\subsubsection{General Occupational safety laws:}

To achieve public safety standards, the following laws must be applied:

- Workers use personal protection equipment during work to prevent accidents,

- Providing first aid equipment to deal with serious and minor injuries at the construction site,

- Create a special zone for chemicals and flammable materials to isolate it from the place where construction workers gathered to avoid accidents,

- Establish exercises for workers to train them to avoid accidents and how to deal with them,

- Work to remind workers of the need to take care of health and safety through posters. Also, posters that are concerned with spreading awareness related to occupational health and safety.

Working to follow these laws is an excellent step to reduce accidents at the construction site, which means maintaining the safety and health of construction workers.

\subsection{Occupational health and safety assurance requirements on construction sites}

According to Toole (2012), several steps reduce accidents and are as follows.

\subsubsection{Construction site lighting}

Many construction projects are carried out most of them at night, and with no light, the rate of accidents increases, and from this standpoint, it becomes necessary to provide the lighting necessary to avoid accidents.

\subsubsection{Securing emergency exits}

Due to the occurrence of accidents on the construction site, with a large percentage, it is securing emergency exit exits is a necessity for occupational health and safety in case any accident the worker can directly go to the safe zone using this emergency exits (Dawson et al., 1985).

\subsubsection{Clean and fresh air}

The health of the workers cannot be ignored, especially at the construction site. They are exposed to more dust and many pollutants that are harmful to their health. In many cases, they cause permanent illnesses. Often, workers work underground with distances that may reach more than 30 meters in this depth ratio. Fresh air is very little to solve such a problem, in order to preserve the life and health of workers, it is necessary to secure fresh air through pure air pumps.

\subsubsection{Safety structure}

One of the biggest causes of accidents that cause major harm to workers is the collapse of structures due to the insecure structure and the absence of periodic monitoring. Such a reason may cause great deaths and injuries to the workers, therefore organizing the construction process with close monitoring in order to avoid any part of the structure being implemented in the wrong way.

\subsection{Distribution of health and safety duties}

In order to achieve the health and safety of all project personnel at the construction site, the responsibilities must be divided and distributed among all those concerned with the project. Choudhry et al. (2008) define the duties are distributed in Table 1.

Table 1. Distribution of health and safety duties

\begin{tabular}{|l|l|}
\hline Roles & Duties \\
\hline Client & $\begin{array}{l}\text { Ensure the design and implementation of the } \\
\text { project by specialized companies }\end{array}$ \\
\hline Contractor & $\begin{array}{l}\text { Eliminating or limiting and controlling } \\
\text { expected health and safety risks, which are } \\
\text { risks that are directly related to design }\end{array}$ \\
\hline Project planning, management and control \\
\hline $\begin{array}{l}\text { The } \\
\text { engineers }\end{array}$ & $\begin{array}{l}\text { The worker must maintain his health, safety, } \\
\text { and the other worker's health and safety by } \\
\text { not performing any work that may cause } \\
\text { accidents, that means working professionally }\end{array}$ \\
\hline $\begin{array}{l}\text { Checking the specifications of machines and } \\
\text { equipment and determining whether they are } \\
\text { working or not, in addition to reviewing the } \\
\text { work plan and identifying and avoiding risks in } \\
\text { order to maintain the safety of the work team. }\end{array}$ \\
\hline
\end{tabular}




\section{EXAMPLE OF THE OCCUPATIONAL HEALTH AND SAFETY MANAGEMENT (ROAD CONSTRUCTION CASES)}

Usually, pre-solutions are discussed and implemented for pre-conditions depending on avoiding halting traffic. In this case, other paths must be secured before starting the maintenance process or implementing a project. This is a case if the road is one path valid for one car, either if it is one path and valid for a number of cars, part of which is covered, which is the workplace, taking into consideration the development of safety guidelines to preserve the lives of workers and the lives of citizens and reduce accidents.

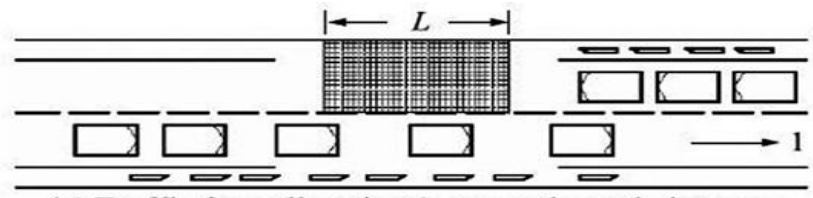

(a) Traffic from direction 1 passes through the zone

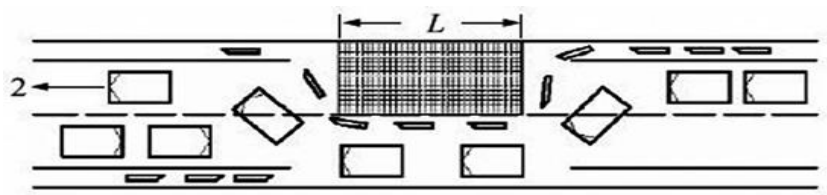

(b) Traffic from direction 2 passes through the zone

Fig. 3. (a-b): Traffic in the two-track work area on one track (Dejus, 2013)

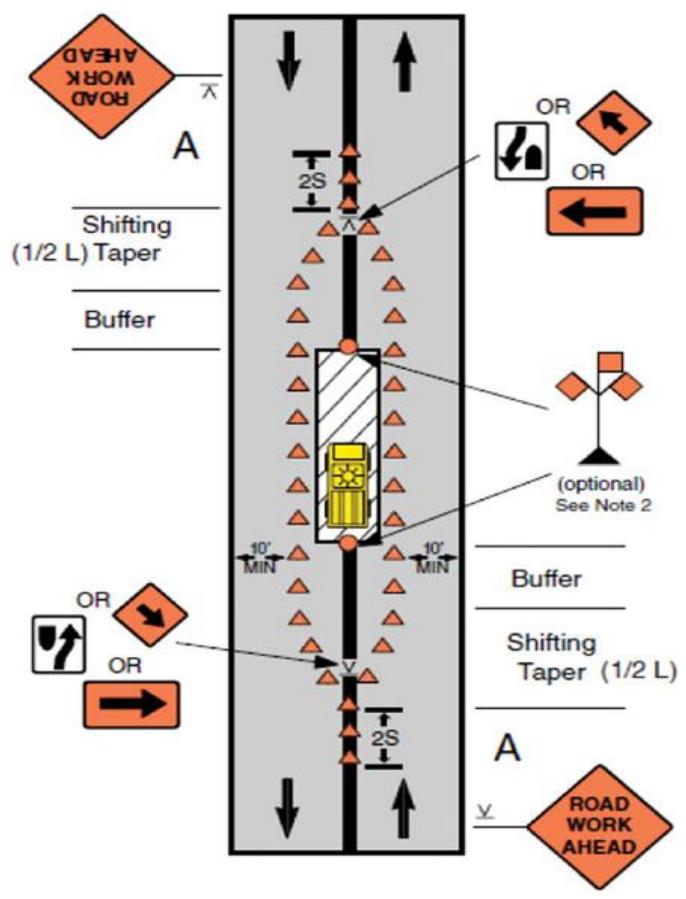

Fig. 4. Traffic in the two-track work area in the middle (Dejus et al., 2013)
In the case of a two-lane road, the diagrams shown in Figs. 3 and 4 illustrate how the process of validation or construction is going to avoid accidents. In Fig. 3 an example is shown to alternate directions in the vicinity of the work area to ensure the continuity of traffic (Dejus et al., 2013).

Fig. 4 demonstrate how the repair process will proceed while ensuring two-way traffic (with speed not exceeding a mile per hour) according to (Transportation Information Center, 2013)

It should be clarified that this process does not completely prevent accidents. Workers may be exposed to some damage or accident during the process of installing these instructions. Also, after starting work, vehicles can enter the workplace and cause damage to workers and people inside the vehicle. Hence the role by informing people that there is a road repair process (Dejus, 2013).

\section{CONCLUSIONS}

When analysing occupational health and safety risks, in the beginning, a focus must be placed on training construction workers on occupational health and safety conditions and the importance of this training to protect everyone from the risk of an accident. This is one of the main reasons for the increase in the number of accidents and the number of wounded, plus the increase in the number of deaths in the construction industry. Either the absence of training or lack of effective training, the authors, analysts and all those concerned with occupational health and safety in the construction industry have presented many suggestions and ideas to reduce accidents. The most important of which is training the construction workers and testing to ensure that the worker makes a reasonable decision in the event of a certain risk.

Road safety solutions were introduced that focused not only on the safety of workers but also focused on the safety of drivers in the event of road restoration or paving the road, and hence the importance of occupational health and safety in maintaining safety for all, workers or citizens.

\section{CONFLICT OF INTEREST STATEMENT}

The author declares that there is no conflict of interest.

\section{REFERENCES}

[1] Smolarz, A. (2019). Analysis of accidents in construction in 2015-2017. Civil and environmental engineering reports 29 (4), 149-156.

[2] Abdul Hamid, A. R., Abd Majid, M. Z., \& Singh, B. (2008). Causes of accidents at construction sites. 
Malaysian Journal of Civil Engineering 20(2), 242259.

[3] Baxendale, T., \& Jones, O. (2000). Construction design and management safety regulations in practiceprogress on implementation. International Journal of Project Management, 18(1), 33-40.

[4] Choudhry, R. M., Fang, D., \& Ahmed, S. M. (2008). Safety Management in Construction: Best Practices in Hong Kong. Journal of Professional Issues in Engineering Education and Practice, 134(1), 20-32.

[5] Dawson, S., Clinton, A., Bamford, M., \& Willman, P. (1985). Safety in Construction: Self-Regulation, Industrial Structure and Workforce Involvement. Journal of General Management, 10(4), 21-38.

[6] Zhang, F., Fleyeh, H., Wang, X., \& Lu, M. (2018). Construction site accident analysis using text mining and natural language processing techniques. Elsevie Automation in Construction, 99, 238-248. https://doi.org/10.1016/j.autcon.2018.12.016

[7] Lingard, H. (2013). Occupational health and safety in the construction industry Construction Management and Economics, 31(6), 505-514.

[8] International Labour Organization (2005) Facts on Safety at Work, International Labour Office, Geneva. https://www.ilo.org/wcmsp5/groups/public/--dgreports/--dcomm/documents/publication/wcms 067574.pdf

[9] Mitropoulos, P., \& Memarian, B. (2012). Team processes and safety of workers: cognitive, affective, and behavioral processes of construction crews. Journal of Construction Engineering and Management ASCE, 138(10), 11811191.

[10] Naujalis, J. (2009). Review of occupational health and safety in 2005-2008. Labour Inspectorate of the Republic of Lithuania (in Lithuanian).

[11] Toole, T. M. (2002). Construction Site Safety Roles. Journal of Construction Engineering and Management, 128(3), 203-210.

[12] Dejus, T., \& Antuchevic, J. (2013). Assessment of health and safety solutions at a construction site. Journal of Civil Engineering and Management, 19(5), 728-737.

[13] Dejus, T. (2013). Typical Solutions for the Construction Site Employees' Safety. Sciverse Science Direct. Procedia Engineering, 57, 238-243.

[14] Guo, S., Ding, L., Zhang, Y., Skibniewski, M. J., \& Liang, K. (2019). Hybrid Recommendation Approach for Behavior Modification in the Chinese Construction Industry. American Society of Civil Engineers, 145(6), 04019035. 